\title{
As formas de nascer entre os Assuriní do Trocará, no município de Tucuruí - Pará
}

\section{Forms of birth among the Assuriní in Trocará, Tucuruí - Pará}

\author{
Benedita Celeste de Moraes Pinto* \\ Maria de Fátima Rodrigues Nunes** \\ Barbara de Nazaré Pantoja Ribeiro***
}

\begin{abstract}
Resumo
O presente estudo analisa as formas de nascer entre os Assurini do Trocará, no Município de Tucuruí, Pará, evidenciando questões culturais, saberes e preceitos religiosos, além das transformações pelos quais estas vem passando a partir das ultimas décadas do século XX. Para tanto, buscamos auxílio teóricometodológico em autores que discutem a temática em questão. Da mesma forma, foi realizada pesquisa de campo mediante a observação participante no cotidiano de mulheres, crianças e demais habitantes desta aldeia indígena. Dados da pesquisa apontam que as formas de nascer entre os Assurini transitam além dos métodos da medicina formal, permeiam questões culturais e religiosas deste povo. Embora muitas alterações tenham ocorrido ainda se observa por parte deste povo resistências em valorizar os modos tradicionais envoltos em saberes, preceitos, traços culturais e religiosos para trazer uma criança ao mundo.
\end{abstract}

Palavras-chave: Formas de Nascer, Transformações e Resistências, Etnia Assurini.

\begin{abstract}
The present study analyses the forms of birth among the Assurini of Change, in the town of Tucuruí, Pará, highlighting cultural issues, knowledge and religious precepts, in addition to the transformations from the last decades of the 20th century. To this end, we seek theoretical-methodological aid in authors that discuss the subject in question. Similarly, field research was carried out by the participant observation in the daily lives of women, children and other inhabitants of this Indian village. Research data shows that the forms of birth among the Assurini go from traditional ways to the methods of formal
\end{abstract}

\footnotetext{
*Doutora em História pela PUC/SP. Coordenadora do Programa de Pós-Graduação em Educação e Cultura da Universidade Federal do Pará, Campus Universitário do Tocantis/Cametá. E-mail: celpinto18@gmail.com

** Mestranda em Educação e Cultura pela Universidade Federal do Pará. E-mail: nunesfatima098@gmail.com

*** Mestranda em Educação e Cultura pela Universidade Federal do Pará. E-mail: barbaracameta@gmail.com
} 
medicine, permeating cultural and religious issues of this people. Although many changes have occurred still is observed on the part of resistance in adding value to traditional modes involved in knowledge, precepts, religious and cultural traits to bring a child into the world.

Keywords: Forms of Birth, transformation and resistance, Assurini Ethnicity.

\section{Considerações iniciais}

O presente estudo está centrado na aldeia indígena Assuriní do Trocará, Município de Tucuruí, no Pará, objetivando analisar as formas de nascer entre os Assurini do Trocará, evidenciando questões culturais, saberes e preceitos religiosos, além das transformações pelos quais estas vêm passando a partir das ultimas décadas do século XX. O território ocupado por essa etnia possui 21.722 hectares e um perímetro de $74 \mathrm{~km}$, regularizada de acordo com o decreto $\mathrm{n}^{\circ} 87.845$ de 22 de novembro de 1982, onde habita aproximadamente 700 indígenas distribuídas em 04 (quatro) aldeias: Trocará que é a aldeia sede, Ororitawa, Oimotawara e Pikiá. Destas apenas a aldeia sede conta com serviços de energia elétrica, água encanada, posto de saúde e escola.

Para o desenvolvimento deste estudo, além de buscarmos apoio teórico metodológico em autores que discutem a temática em questão, também realizamos pesquisa de campo na Aldeia Trocará com observação participante no cotidiano de mulheres, crianças e demais habitantes desta aldeia indígena, gravação de entrevistas e conversas informais.

A oralidade, assim como as demais fontes de pesquisa, tem importância relevante, pois, conforme afirma Thompson, a história oral é uma ferramenta que se baseia na memória dos sujeitos para questionar interpretações deturpadas feitas sobre fatos ou alguns povos. É através de entrevistas que os sujeitos da pesquisa contam as suas experiências. A história oral "pode ser utilizada para alterar o enfoque da própria história e revelar novos campos de investigação"; pode devolver as pessoas que fizeram e vivenciaram a história um lugar fundamental, mediante as suas próprias palavras. ${ }^{1}$

Por outro lado, a observação participante como uma técnica de pesquisa é essencial para ser trabalhada quando o(a) pesquisador(a) se propõe a

${ }^{1}$ THOMPSON, Paul, 1935- A voz do passado: história oral/ Paul Thompson; tradução Lólio Lourenço de Oliveira. -Rio de Janeiro: Paz e terra, 1992, p. 22. 
fazer uma pesquisa científica, mas se relaciona diretamente com os sujeitos desta, participando do seu cotidiano, de sua vida cultural, com objetivos de coletar dados e compreender as relações socioculturais e hábitos de um grupo especifico, ${ }^{2}$ como ocorreu na Aldeia indígena Assuriní do Trocará, onde tais metodologias foram de extrema importância para que pudéssemos estabelecer contatos mais diretos com seus habitantes e assim buscar verificar como são constituídas as relações culturais, religiosas e as formas de nascer entre esta etnia indígena.

As formas de nascer são especificas de acordo com cada sociedade ou povo. Embora, no sentido biológico científico as ações para que uma criança nasça sejam parecidas nas diferentes sociedades, as formas e maneiras que isso ocorre se diferenciam de acordo com questões culturais e a realidade de cada povo. Para Mendonça, toda forma de obstetrícia é cultural, pois cada povo tem características especificas de realizar este procedimento, como por exemplo, boa parte das mulheres da Índia dá a luz em pé. Assim, coisas que acreditamos serem naturais, como o parto na posição deitada de costas, não são mais naturais do que outras, como o fato de mulheres de alguns grupos indígenas realizarem o parto de cócoras, são questões culturais que devem ser respeitadas. ${ }^{3}$

Segundo Morais, entre os séculos XVII a XIX muitas diferenças em relação ao parto eram apresentadas por várias sociedades. Entre os europeus, por exemplo, o momento do nascimento era transformado em um evento social, onde as mulheres que estavam prestes a dar à luz chamavam amigas e familiares para ajudar em tal ato, era assim um momento de comemoração. Já no Japão, o ato de nascer era classificado como algo totalmente perigoso, sendo carregado de misticismo, acreditando-se que, tanto a mãe, como a criança estavam entre o mundo dos vivos e dos mortos, precisando de vestimentas e lugares específicos para a realização do parto. Enquanto entre alguns grupos indígenas americanos, o ato de nascer era tido como um evento natural e íntimo, no qual as mulheres preferiam parir sozinhas, longe dos demais membros de sua aldeia ou comunidade, retornando as suas atividades do dia

\footnotetext{
${ }^{2}$ CORREIA, Maria da Conceição Batista. A observação participante enquanto técnica de investigação. Pensar Enfermagem. Vol. 13 n.2. 2º Semestre de 2009. Disponível em:< http://pensarenfermagem.esel. pt/files/2009_13_2_30-36.

${ }^{3}$ MENDONÇA, Sara Sousa. "Mudando a forma de nascer: agência e construções de verdades entre ativistas pela humanização do parto", dissertação de mestrado, Universidade Federal Fluminense. Niterói/RJ, 2013, p. 12 a 13.
} 
a dia e ao convívio social após o nascimento dos filhos, agindo como se nada tivesse ocorrido. ${ }^{4}$

Portanto, em relação ao ato de nascer há significados e interpretações que se diferenciam de um povo para outro. Morais afirma que os diferentes acontecimentos que envolvem as sociedades interferem no ato de parir e nascer, consequentemente, isso também abarca essas mudanças, os cuidados que são dados a esses atos se diversificam de acordo com cada espaço. Desta forma, antes de ser um evento médico, o parto é um acontecimento biológico transformado em atos culturais, pois pode ser realizado de acordo com os hábitos e costumes de uma determinada sociedade. ${ }^{5}$

Para Mendonça, as mudanças são evidentemente sentidas no que diz respeito as formas de realização dos partos na sociedade ocidental, pois muito foi modificado nas formas de nascer no decorrer das décadas, como exemplo, a prática dos partos naturais no Brasil, que atualmente está cada vez mais sendo substituída por um crescente número de cesarianas, que atinge um percentual de $56 \%$ dos partos realizados no pais, destes, $84 \%$ são realizados no sistema privado e $40 \%$ pelo SUS (Sistema único de Saúde), embora que em muitos casos tal opção seja totalmente desnecessária, devido a mãe e nem o bebê passarem por algum tipo de risco, quando o parto cesariano é mais indicado. ${ }^{6}$

No decorrer do processo histórico as maneiras de nascer, trazer uma criança ao mundo mediante o parto, se diferenciam de uma sociedade para outra ou entre povos. Da mesma forma, todos os processos que estão ligados ao nascimento, como os tratamentos pré e pós-parto, as formas de alimentação e as crenças que dizem respeito a este momento, também, se distinguem de um povo para outro. Neste sentido, práticas que eram realizadas por muitos povos em séculos passados passaram por transformação de acordo com os acontecimentos e as mudanças sociais e culturais ao longo do tempo.

Tais mudanças são sentidas também nas diferentes etnias indígenas, como na Assurini do Trocará, no Município de Tucuruí, no Pará que diante dos processos de contato e as relações estabelecidas com outras sociedades,

\footnotetext{
${ }^{4}$ MORAIS, Fatima Raquel Rosado, “A Humanização no Parto e no Nascimento: Os Saberes e as práticas no contexto de uma maternidade pública brasileira”. Tese de Doutorado, Universidade Federal do Rio Grande do Norte. Natal/RN, 2010, p. 25 a 26.

${ }^{5}$ Ibidem, p. 27.

${ }^{6}$ MENDONÇA, op. cit., p. 14.
} 
outras culturas e costumes, convivem com as alterações dos diferentes hábitos e rituais praticados no interior de suas comunidades. ${ }^{7}$

$\mathrm{Na}$ aldeia indígena Assuriní do Trocará localizada no Município de Tucuruí, dados das pesquisas ${ }^{8}$ que estamos realizando apontam que tais questões são fortemente vivenciadas, como é o caso do ato de nascer, pois há décadas era algo voltado exclusivamente para o interior da aldeia, onde as mulheres davam à luz a seus filhos sós ou com auxílio do pajé e de parteiras, que lhes prestavam assistência desde o primeiro momento da gravidez até o após parto. Atualmente raramente ocorrem partos dentro da aldeia Trocará, pois tão logo as mulheres Assurini entram em trabalho de parto são imediatamente encaminhadas para o hospital da cidade de Tucuruí, onde nascem seus filhos.

Isso ocorre sob a alegação de que todo o acompanhamento pré-natal da parturiente é realizado pelos profissionais de saúde que atuam na aldeia Assurini do Trocará, como as consultas e exames periódicos direcionados ao acompanhamento do pré-natal. Os procedimentos da medicina formal passam a exercer domínio nas manobras do parto e do nascer em detrimento as práticas, costumes e rituais tradicionais do nascimento, do parir, o que causa desagrado a muitos Assuriní, principalmente aos mais idosos, que resistem, buscando assegurar e valorizar seus traços culturais e religiosos, reivindicando melhores condições de atendimento no posto da aldeia Trocará, para que os nascimentos das crianças Assurini ocorram dentro desta aldeia.

\section{Formas de reproduçao entre as mulheres Assurini}

Questões relacionadas a reprodução e a saúde da mulher indígena ainda é carregada de tabus, ausências e duvidas, devido haver poucas pesquisas e materiais que abordem tal temática. De acordo com os dados de algumas pesquisas antropológicas realizadas entre algumas etnias indígenas, como destaca Mendonça, as mulheres indígenas tendem a ter mais filhos do que as

\footnotetext{
${ }^{7}$ PINTO, B. Celeste de Moraes; SOUZA, Susana Braga; PROCóPIO M. Gorete Cruz. "Falaram de Extinção, Mas Nós Resistimos” : história e memória do povo Assurini do Trocará. Editora da UFPA/Campus Universitário do Tocantins, 2014, p. 26.

${ }^{8}$ A partir de 2012, vêm sendo desenvolvidos alguns estudos na Aldeia Assurini do Trocará, principalmente, por pesquisadores ligados a pesquisa História, Educação e Saberes Tradicionais na Amazônia, coordenada

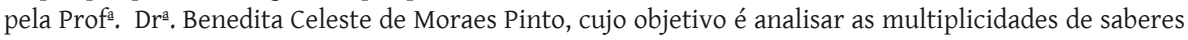
existentes entre as populações indígenas da região do Tocantins - norte da região Amazônica, das quais se destaca os Anambé, no município de Mojú, os Assurini da Reserva Trocará, no município de Tucuruí e os Tembé (Aldeia Pitawa), no município de Tomé-Açu, visando conhecer desde a constituição histórica, tipos de educação, língua oficial, relações de gênero, questões culturais e religiosas de tais povos.
} 
não indígenas, fato que é justificado por diversos fatores, como a valorização sociocultural de famílias numerosas entre estas populações; de acordo com os padrões ocidentais, o inicio precoce de mulheres indígenas na atividade sexual e o intervalo menor de um parto para outro. Tais questões ainda são carregadas de segredos e carecem de mais esclarecimentos para que sejam trazidos à tona. ${ }^{9}$

Entre os Assuriní do Trocará, assim como, em muitas etnias indígenas, falar de tais assuntos ainda carrega certas limitações, pois as mulheres Assuriní restringem-se em falar algo tão peculiar de suas intimidades com pessoas com as quais não têm contatos. Sendo necessário primeiro que se conquiste a confiança destas mulheres para que se tenha algum tipo de informações, mesmo que limitada, a respeito das relações que estabelecem com seus parceiros, do cuidado com a saúde e da concepção reprodutiva.

As primeiras relações sexuais entre meninos e meninas Assuriní acontecem ainda na adolescência, marcando um ato de passagem de criança para a fase adulta, na qual assumirá responsabilidades. Geralmente os Assurini começam a se relacionar a partir dos oito ou dez anos de idade, quando começam namorar. As pessoas entrevistadas no decorrer da pesquisa narram que antigamente esta espécie de compromisso era assumida pelas famílias, os pais faziam acordo e contrato de casamento quando seus filhos ainda eram crianças, que sem confirmavam quando estes cresciam. Atualmente estes tipos de compromissos são mais diretos, ocorrem através do gostar e dos sentimentos nutridos através da convivência. O namoro entre os Assurini começa geralmente em idades precoces, se comparado a sociedades não indígenas, sendo consolidado geralmente aos 13 ou 14 anos.

Atualmente, raramente acontecem casamentos na Aldeia Trocará, seja na cultura indígena ou regularizado pela sociedade não indígena. Mas os indígenas mais velhos contam que os casamentos eram frequentemente realizados entre eles no início da formação da aldeia Trocará, quando muitas vezes os noivos nem se conheciam, sendo que o casamento era confirmado pelo cacique geral, que entregava ao homem um arco e uma flecha, que simbolizavam os instrumentos essenciais, com o qual deveria sustentar a sua família. As vestes geralmente eram de palha para os homens, enquanto as mulheres permaneciam nuas. Nos dias atuais, é comum que os genros falem com os pais das moças para que concedam a união dos dois, mas primeiramente a mulher fica morando na casa de seus pais, pois a convivência entre os dois somente

${ }^{9}$ MENDONÇA, op. cit., 2013. 
será oficializada quando nascer o primeiro filho do casal. A partir de então constroem sua casa e formam o seu núcleo familiar.

Os Assurini contam que logo após os primeiros contatos com a população não indígena, e durante seu estabelecimento nas terras Trocará passaram por um grande processo de depopulação devido contraírem doenças até então desconhecidas por eles, como gripe e disenteria, que ceifaram vidas de indígenas de todas as idades. Em relação a tal questão, Laraia, em pesquisa realizada entre os meses de setembro a novembro de 1962 entre os indígenas Asurini, verificou que era um grupo muito pequeno, constituído de 12 homens, 07 mulheres, 10 meninos e 06 meninas, além de ter tomado conhecimento da existência de outros pequenos grupos Asurini, dispersos pela grande floresta entre os rios Tocantins e Xingu. ${ }^{10}$

Para tentar fugir da extinção, aumentar a população e garantir a sobrevivência do grupo, os Assurini do Trocará passaram a aceitar os incentivos, através das ações da Fundação Nacional do Índio (FUNAI), para a realização dos casamentos só entre os jovens Assuriní, e proibiam o uso de qualquer forma contraceptiva que impedisse a gestação e consequentemente o nascimento de crianças indígenas. Essa foi uma política desenvolvida pela FUNAI, no decorrer da década de 1954, para provocar o aumento da população indígena. Neste período os Assuriní passaram habitar a área do Trocará e ao estabelecerem contatos mais diretos com não indígenas da região adquiriram doenças, como a disenteria e gripe, que provocaram intensa mortandade desta população indígena, beirando a sua extinção. ${ }^{11}$

O resultado de tal ação é observado atualmente entre os Assurini, pois os casais mais velhos da aldeia Trocará possuem números de filhos elevados, indo de treze ou mais filhos. Observou-se durante a pesquisa que há muita simpatia de jovens indígenas pela família numerosa, pois dizem que devem seguir a tradição dos mais velhos, e acham bonito ter uma família grande. Conforme a fala Imuinawa Assuriní.

Por que primeiro, né, essas mulheres mais idosas que tão, elas teve filho, tem uma ai que tem treze filhos, né, tem treze filho, a outra tem dez, tem onze, tem 12 né. Agora com esse remédio, agora que entrou, né, as meninas não querem mais ter filho, às vezes elas casam, ai toma

\footnotetext{
${ }^{10}$ LARAIA, Roque de Barros. Recordando Teapykawa, Informante Feminina Asurini. In: Habitus. Goiânia, Volume 13, n. 2- 16, jul./dez. 2015, p. 5.

${ }^{11}$ LARAIA, Roque de Barros \& DA MATTA, Roberto. Índios e Castanheiros: a empresa extrativista e os índios do médio Tocantins. Paz e Terra : Rio de Janeiro, 1978, p. 35
} 
remédio, ai quando ela pensa em ter filho, tem um, tem dois, e não quer ter mais, assim como nós, né, pira. Eu tenho sete, ai é assim. ${ }^{12}$

Assim, muitos casais jovens são contra a ação e introdução de métodos contraceptivos dentro da aldeia Trocará, alegam ir contra as tradições estipula o número de filhos dos casais. Tal argumento ganhou apoio das ações da FUNAI, que chegou a proibir o uso de anticoncepcionais pelas mulheres Assuriní, como incentivo para promover o aumento populacional desses indígenas. O resultado de tal incentivo, segundo foi observado por Pinto, Souza e Procópio, nos dias atuais os Assurini contabilizam mais de 700 pessoas, entre adultos, jovens, idosos e crianças. ${ }^{13}$

Atualmente está população indígena designa as mulheres a escolha de usar ou não os medicamentos contraceptivos. Se optarem por utiliza-los, podem encontrá-los no posto de saúde da aldeia Trocará, no qual os profissionais de saúde fazem sua distribuição. Contudo, continua sendo proibido a laqueadura, exceto para aquelas mulheres que têm alguns problemas de saúde durante a gravidez ou que correm algum risco de vida.

Eu acho que eu vejo um lado assim, eu vejo um lado assim que, que é bonito né a pessoa ter uma família assim grande né, é por que sem a criança ali, não tem alegria, né eu acho que é a criança que faz a alegria numa casa, né você chega ai seu filho vai chamar lá vem papai né, lá vem mamãe né, uma coisa tão bonito que de ouvir assim, a voz de uma criança, lá dentro né, acho que por que se não tiver nadinha ali não tem alegria ali naquela casa né, eu vejo dessa forma também, mas agora não, agora tem como evitar por que tem o remédio que é pra evitar, ai hoje em dia muitos não querem ter filho por que querem trabalhar né, então por que se você ter filho ai você vai dar atenção pro seu filho ai você vai deixar de arranjar um emprego né de trabalhar, mais assim agora, tem esse medicamento que pra evitar e muitas mulheres não querem ter mais filhos. ${ }^{14}$

Tal fato divide as opiniões dentro da comunidade, entre aqueles que apoiam tal medida e aqueles que são contrários a ela como o professor Toriawia Assuriní.

\footnotetext{
${ }^{12}$ Fala da indígena Imuinawa Assuriní, 32 anos, habitante da aldeia Assurini do Trocará. Entrevista realizada em outubro de 2015.

${ }^{13}$ PINTO; SOUZA; PROCÓPIO, op. cit., p. 11.

${ }^{14}$ Fala de Pirá Assuriní, liderança indígena, outubro de 2015.
} 
FUNAI não deixava né é entrou várias técnicas ai né sempre procurei, vendo o lado também da comunidade, não vendo o lado de população no caso de aumentar a população, mas vendo as condições financeira né, na alimentação da criança até da educação eu já pensava nisso no caso tinha pai que passava necessidade né com as crianças, é teve uma época ai que é que não tava tendo rede, entendeu, as criança tava adoecendo, né, porque dormia no chão, então não é por que eles queriam né era porque tava difícil mermo porque a maioria não tinha emprego depende da coleta do açaí, peixe, caça então tava difícil então chegando a essa conclusão sempre conversei com a enfermeira né, sempre a FUNAI era contra, não pode esse controle porque tem que aumentar a população indígena, mais tinha esse lado o que adianta ter muita criança se a gente não consegue manter né dá o que ele precisa o conforto que ele precisa. ${ }^{15}$

A preocupação com os filhos e de como manter a família são as principais causas que fazem os Assuriní buscarem limitar o número de filhos, visto que muitos não possuem trabalho formal, se mantendo da caça, da pesca e da coleta de frutos. Embora atualmente os produtos destas atividades tenham se tornado escassos, motivo pelo qual alguns Assurini dizem que são totalmente a favor dos métodos contraceptivos, afirmando que não adianta ter muitos filhos se não tem como mantê-los, ou mesmo nem onde dormir, então é necessário olhar esse outro lado do cuidado, da sobrevivência. Neste sentindo, defendem que cabe a própria mulher decidir e limitar quantos filhos quer ter ou parir, havendo na aldeia Trocará mulheres que querem continuar tendo seus filhos, como suas avós, mães e tias que concebiam e davam a luz enquanto tivesse em idade reprodutiva, sem fazer uso de nenhum tipo de contraceptivo, e aquelas que preferem ter poucos filhos e por isso fazem uso deste, e suas as escolhas e opiniões são respeitadas, pois temem que não consigam dar o melhor para seus filhos.

Para as mulheres grávidas e aquelas que fazem acompanhamentos de saúde, os atendimentos são realizados dentro da própria comunidade no posto de saúde, somente os casos específicos, como partos e casos graves de saúde são encaminhados para a cidade de Tucuruí, em companhia da enfermeira ou técnicas de enfermagem. Os acompanhamentos com ginecologistas são feitos periodicamente, sendo realizados a cada seis meses o PCCU (Prevenção do Câncer do Colo do Útero), coletas de Urina e demais exames de prevenção a alguma doença, como: infecções ou possíveis DSTS (Doenças Sexualmente

${ }^{15}$ Fala de Toriwaia Assuriní, professor de língua indígena na aldeia Trocará, outubro de 2015. 
transmissíveis). Segundo as enfermeiras ligadas ao posto de saúde da aldeia Trocará, nenhum caso de doenças sexualmente transmissíveis foi computada ultimamente nesta aldeia, destacando que as mulheres Assuriní fazem periodicamente todos os acompanhamentos necessários, ao contrário dos homens que não se consultam regularmente com especialistas, devido serem mais despreocupados com questões relacionados a saúde. Os partos eram realizados por parteiras dentro da própria aldeia, mas com a instalação do posto de saúde essas profissionais ficaram inibidas de exercer esses ofícios, e as mulheres são deslocadas para a cidade de Tucuruí para ganhar bebê.

Eu fiz meu pré-natal de todos três aqui na aldeia, ai quando eu ia pra, quando
chegava o tempo de ganhar ele, ai me leva pra cidade foi só ele que nasceu
no meio da viagem né é faltando $7 \mathrm{~km}$ pra chegar lá em Tucuruí, nasceu no
meio da viagem, mas se desse tempo ele ia nascer lá também, ai os outros tudo
nasceram lá, quando chegava pertinho do dia eu pra casa da minha mãe com
medo de acontecer o que aconteceu com ele, o primeiro né, ai chegava lá ia
pro hospital ganhava, sempre fiz pré-natal, sempre fiz aqui todas as minhas
consultas eu faço aqui entendeu. ${ }^{16}$

As mulheres e seus filhos fazem as consultas periódicas pós-parto dentro da própria aldeia, no qual recebem medicamentos necessários para a recuperação, tais como: vitaminas ou antibióticos, medicamentos estes de origem não indígenas, mas os cuidados tomados não se limitam a isso, elas seguem muito de sua cultura, geralmente subsidiadas por suas mães ou avós, que buscam sempre cuidar desse período de acordo com seus costumes.

Evidencia-se, desta forma, a mescla de saberes existentes entre os Assuriní, visto que, ao mesmo tempo em que buscam manter seus saberes tradicionais, também se beneficiam com os saberes influentes da cultura não indígena, fato justificável, uma vez que os processos culturais estão em constante movimento e as mudanças sociais no qual estão inseridos possibilita-os também a se beneficiarem de traços culturais não indígenas.

Conforme defende Almeida, a tradição está sofrendo mutações frequentemente, pois o meio que um povo ou grupo está inserido oferece-lhes novas possibilidades de transformação, sendo assim uma prática realizada entre um povo indígena pode ser ressignificada e transformada, sem que para isso deixem de ser indígena, apenas estão, assim como qualquer outra sociedade, interagindo com o meio envolvente. ${ }^{17}$

\footnotetext{
${ }^{16}$ Fala de Joana Assuriní, outubro de 2015.

${ }^{17}$ ALMEIDA, Maria Regina Celestino de. Os Índios na história do Brasil- Rio de Janeiro: Editora- FGV, 2010. Pg. 25.
} 
Os Assuriní contam que, quando não existia posto fixo da Fundação Nacional de Saúde (FUNASA) na aldeia Trocará, se tratavam com pajé e com os remédios feitos de ervas curativas, ou então eram obrigados sair da aldeia em busca de atendimento médico na cidade. Após a instalação do posto de saúde nesta aldeia em 1994, passaram a contar o "atendimento de saúde vindo dos brancos", mas dizem que ainda não abandonaram a crença no pajé, com quem até hoje os doentes são tratados. O último pajé dos Assuriní do Trocará foi Nakawa'é Assuriní, já falecido, cujo espírito acreditam está em uma onça, que passeia constantemente pela reserva Trocará. ${ }^{18}$

Desta forma, sempre buscam manter seus traços e costumes, fato evidenciado em relação a forma de nascer entre os Assurini, que além contarem com o atendimento dos profissionais do posto de saúde da aldeia Trocará, também é comum as mulheres grávidas buscarem o acompanhamento de um pajé, que desempenha a função de orientar e cuidar destas mulheres, através de massagens na barriga e orientações de remédios caseiros para terem um parto tranquilo. Devido não haver atualmente pajé entre os Assurini, essa função é exercida pelo pajé Valdemar Munduruku, cujo papel que desempenha é visto como de extrema importância para essa população indígena. Porém é uma atividade carregada de segredos, pois muitas informações sobre seu trabalho não podem ser reveladas. As mulheres entrevistadas afirmam que o trabalho do pajé é essencial para que os partos sejam rápidos e seguros.

Ele puxa nossa barriga e ajeita nossa criança no lugar certo para nascer, aí a gente vai pro hospital só pra dar à luz, o médico só pega a criança que o pajé ajeitou. Ele sempre puxa a noite a barriga e sempre acompanhada da mulher que ajuda ele. ${ }^{19}$

Nesse relato notamos a importância exercida pelo pajé, vale ressaltar que ele é uma espécie de pajé coletivo, atua em entre várias etnias indígenas da região já que algumas, como a Assurini, não tem pajé em atividade. Valdemar Munduruku é uma espécie de médico e parteiro que no caso de uma emergência realiza partos. Este também orienta o que as mulheres devem fazer para se manterem saudáveis, assim também como seus filhos, fato também evidenciado por outros moradores mais velhos da aldeia Trocará:

Dentro da comunidade minha tia conta né e até hoje a mãe e o pai não pode comer peixe, por exemplo, o Piaú, não pode comer, cabeça de peixe, não pode

\footnotetext{
${ }^{18}$ PINTO; SOUZA; PROCÓPIO, op. cit., p. 14.

${ }^{19}$ Fala de Muira Assurini, gestante de 6 meses, entrevistada em 06 de julho de 2016.
} 
comer banana, não pode comer esses peixes de pele assim que não tem escama, caça normal, agora só o caititu homem come caititu, agora muié não pode, ai pode, cuati também a mãe não come e nem o pai, não pode comer, prejudica a mãe e o bebê. ${ }^{20}$

Muitos alimentos são considerados remosos, ${ }^{21}$ ou seja, podem fazer mal para a mãe e para a criança, até mesmo ao pai, pois acreditam que pode provocar danos graves:

Pra comida também não pode comer nada de comida remosa, como caititu, cutia também faz mal, paca também faz mal, peixe que não tenha escama também, é várias coisas que também não pode comer. Também quando a gente tá de bebê novo não pode pegar pena de arara, pena de papagaio, não presta comer macaco, nem guariba, e comer as coisas, que coati que dá coceira, é muita coisa que não pode comer, também faz mal pra criança, porque quando ele ta novinho. Porque tem um rapaz que foi esses dias, mês passado, filho dele nasceu, ele não sabia, não esperava né que o filho dele tinha nascido, ele pegou no papagaio, papagaio tava vivo e passou aqui perto de casa ai o filho dele faleceu, foi na hora, foi fatal, morreu o bebê dele na hora que ele pegou no papagaio, é porque ele pegou o papagaio é porque não pode pegar o papagaio nem pena de arara. ${ }^{22}$

As restrições não se estende apenas a alimentação, como a alguns tipos de caças, peixes, consumo de ovos, seja de galinha ou pássaros, são proibidas por toda a família, por acreditarem que prejudicam a saúde, tanto da mãe como das crianças. Neste sentido, tomam cuidado para não manusear penas de pássaros, como arara e papagaio, que, conforme suas crenças provocam susto no bebê ou ainda choro muito forte e constante, que podem ocasionar até mesmo a morte da criança. Percebe-se, assim, que entre os Assurini existem cuidados específicos da sua própria cultura em relação ao parto e pós-parto, que persistem. Pois, muitos dos seus costumes são mantidos e perpetuados para futuras gerações, através do aprendizado das crianças que mediante observação no seio familiar começam a repassar também esse aprendizado, o que é essencial para a perpetuação dos saberes do seu povo.

Tais questões relacionadas ao sobrenatural desta população indígena, se caracterizam também em relação as formas de concepção da criança Assuriní. Andrade afirma que, nos primeiros momentos de formação da aldeia Trocará,

\footnotetext{
${ }^{20}$ Fala de Itiaíma Assuriní, outubro de 2015.

${ }^{21}$ Entre os Assurini são considerados "remosos" ou "venenosos" algumas tipos de frutas e alimentos fortes ou gordurosas, que "fazem mal" as pessoas, acarretando desarranjo intestinal, infecções e doenças no útero da mulher que se encontro no reguardo do parto, também pode prejudicar a cicatrização do umbigo do bebê, que indiretamente ingere a alimentação através do leite materno.
}

${ }^{22}$ Fala de Wanderleia Assuriní, outubro de 2015. 
onde realizou sua pesquisa de mestrado, os Assuriní acreditavam que a figura feminina era a única a ter contato com Mahíra, o ser espiritual maior desse povo indígena, e que era através dos sonhos que Mahíra tinha relações sexuais e engravidava as mulheres, enquanto os homens eram apenas agentes que nutriam o feto com o sêmen. ${ }^{23}$

Embora isso não seja muito falado atualmente entre esse povo, devido a maioria dos mais velhos, que são os detentores de saberes e segredos, não residirem mais na aldeia Trocará, mas tal questão não descaracteriza essa crença em relação a Mahíra. Mesmo de maneira tímida as falas dos moradores deixam escapar a relação simbólica que esse ser representa e o quanto deve ser respeitado. Como fica evidente na fala de Peppe Assuriní,

Mamãe fala pras filhas dela, olha não faz isso, e se tu fizer Mahíra vai fazer tu ficar grávida. Por que Mahíra não gosta de ninguém desobediente. ${ }^{24}$

Podemos perceber através desta fala de Peppe Assuriní que embora não diga diretamente que Mahíra é quem fecunda a mulher, gera a criança, e por vezes até neguem essa questão, essa crença é ressignificada. Pois diferente dos mais velhos que afirmavam que a formação da criança era feita por esse deus, atualmente Mahíra é usado para chamar a atenção dos jovens para o respeito com os mais velhos, caso contrário podem ser castigados, sendo que para a mulher o castigo pode ser uma gravidez.

Diante disso percebemos que as relações entre o gerar, o nascer e as crenças que envolvem este processo nesta comunidade, vai muito além do campo médico cientifico, perpassa pelo simbólico, pela espiritualidade religiosa que a todo momento permeia as relações deste povo indígena.

\section{O nascer Assurini}

Atualmente as crianças Assuriní geralmente nascem através do parto normal realizado em hospital público na cidade de Tucuruí, portanto, fora da aldeia Trocará. Contudo, contam que atualmente está aumentando o número de parto cesariano, o que foi observado durante a pesquisa, quando visitamos uma mulher Parakanã casada com um Assurini, que se recuperava do parto de sua filha, nascida através de uma cirurgia cesariana. Este fato vem despertando preocupação nas lideranças indígenas da Aldeia Trocará, conforme se observa

\footnotetext{
${ }^{23}$ ANDRADE, Lucia M. M. "O Corpo e o Cosmos. Relações de Gênero e o Sobrenatural entre os Asuriní do Tocantins". Dissertação de mestrado. USP, 1992.

${ }^{24}$ Fala de Peppe Assuriní, professor indígena da aldeia Assuriní, entrevista realizada em julho de 2016.
} 
na fala do Cacique Poraké Assurini, uma dessas lideranças entrevistadas por ocasião da pesquisa:

Inclusive nos estamos lutando pra voltar a parteira porque as criança nasce através da cirurgia, mas é a onde a cultura se perde, tanto Parakanã quando o nosso aqui, tem uma do Parakanã aqui que fez três vezes cirurgia. O pessoal da saúde disse que não tem espaço pra parteira atual aqui. Mas não é que não tem espaço era pra ter uma parteira pra indicar as mulheres como é pra fazer. Porque eu pequei um estudo com a índia Teapekawa que foi parteira também ai ela indicava que num livro que ela escrevia ai eu perguntava: - Nazaré, a gente chamava de Nazaré pra ela, o que é isso aqui? Ai ela dizia: - isso aqui eu fiz, isso aqui é assim quando criança estiver parado não pode ficar esforçando a mulher pra ter, agora quando criança se meche ai tu pode fazer força e a parteira acompanha com puxação. A criança se mexe pra um lado a parteira puxa o outro. A índia Teapikawa escreveu tudo como é como nasce como corta o cordão umbilical. ${ }^{25}$

A partir fala do Cacique Poraké Assurini é possível perceber que há exigência e preocupação para que as mulheres deem a luz a seus filhos mediante o parto natural dentro da Aldeia Trocará. Contudo, observamos que em relação aos partos das mulheres há uma grande interferência dos funcionários do posto de saúde instalado na aldeia, que encaminham as mulheres em trabalho de parto para o hospital de Tucuruí, sob a alegação de não haver espaço para acontecer o parto normal, com auxílio das parteiras na aldeia, o que causa descontentamento dos indígenas, principalmente dos mais velhos que prezam pelo parto normal.

Na aldeia Trocará, o parto é acompanhado pelo pai e pelo futuro padrinho da criança, que no momento do nascimento é quem corta o cordão umbilical:

Por exemplo, eu quero ser padrinho do teu filho sendo teu irmão é eu que corto o umbigo do teu filho se fosse homem, se for mulher é outra pessoa que corta. Ai eu corto e fico sendo padrinho do teu filho. $O$ batismo o capitão vem né escolhe o nome, ai ele põe o nome da criança, ai ele pega, ele banha, dá pro padrinho e entrega pra mãe, depois que a criança amadurece escolhe a madrinha. ${ }^{26}$

O nascimento de uma criança é visto entre os Assurini como um momento de grande felicidade, cheio de significados e ritualizações, como se

\footnotetext{
${ }^{25}$ Fala de Puraké Assurini, uma das lideranças da aldeia Trocará, entrevistado em 12 de outubro de 2015.

${ }^{26}$ Fala do Cacique Puraké Assurini, uma das lideranças da aldeia Trocará, entrevista realizada em 12 de outubro de 2015.
} 
observa através da fala do cacique Poraké Assurini. A partir do nascimento a criança vai sendo inserida nessa sociedade indígena, onde há todo um aprendizado, no qual homens e mulheres recebem funções conforme o sexo do bebê, até o momento do batismo. Este ultimo, se dará só mais tarde, nas águas do rio Trocará na presença dos familiares, em que o nome da criança é escolhido pelo Cacique geral. Momento de extrema importância, o batismo é um ritual que vai inserir a criança a uma identidade étnica, refletida através da escolha do nome e do sobrenome Assurini.

Da mesma forma, torna evidente também o papel dos idosos dentro da aldeia, que devido sua experiência de vida são capacitados para escolher o nome da criança de acordo com características físicas desta.

Para as populações indígenas, as crianças nascem vulneráveis, por isso precisam de atenção especial e cuidados. Clarice Cohn afirma que,

a vulnerabilidade da criança se dá pela ainda débil relação de seu corpo com o karon, que está expresso no tratamento do corpo e na preocupação em tratar sua pele para que se torne "dura" e "forte", assim como pela preocupação em manter o karon interagindo com os vivos, presente no mundo dos vivos, especialmente nos momentos de maior risco de se extraviar, como quando a criança está zangada e querendo se distanciar. Uma maior conexão entre seus elementos constitutivos e, claramente, o fortalecimento de suas relações com os vivos, são a garantia de uma menor vulnerabilidade de ser atraído pelos mortos. ${ }^{27}$

Conforme analisa Cohn, nas comunidades indígenas as crianças são consideradas suscetíveis aos karoaras, espíritos ruins e bons que rodeiam as extremidades de seus territórios. Segundo Andrade, é preciso dominar a força do Karowara, o quê implica em responsabilidades e também em perigo, por isso é preciso haver um amadurecimento não só biológico como social e esse amadurecimento se alcança se tornando adulto e participando intensamente das atividades rituais. ${ }^{28}$ Portanto, desde seu nascimento a criança passa por cuidados, e por vários rituais, usam amuletos para se protegerem de quebrantos, maus olhados e dos Karoaras ruins.

Ao nascer, a criança tem o corpo todo pintado com tinta de jenipapo ${ }^{29}$ para se proteger contra os karoaras, pois ainda não tem autodefesa. Segundo

\footnotetext{
${ }^{27} \mathrm{COHN}$, Clarice. "A criança, a morte e os mortos: o caso dos Mebengokré-Xikrin. Horizontes antropológicos”, Porto Alegre, ano 16, n. 34, p. 93-115, jul./dez 2010, p. 173 - 174.

${ }^{28}$ ANDRADE, Lucia M. M. “O Corpo e o Cosmos. Relações de Gênero e o Sobrenatural entre os Asuriní do Tocantins”. Dissertação de mestrado. USP, 1992, p. 109.

${ }^{29} \mathrm{O}$ jenipapeiro (Genipa americana) é árvore da família Rubiaceae que chega a vinte metros de altura, cujo fruto é o Jenipapo. É encontrado em toda a América tropical. Em guarani, jenipapo significa "fruta que
} 
analisa Cohn, o espírito das crianças não está fixo por completo ao corpo, e somente com seu amadurecimento é que ambos irão se completar. ${ }^{30}$ Entre os Assuriní é passado no corpo das crianças recém-nascidas a goma ou resina extraída do inajazeiro ${ }^{31}$. Os Assurini acreditam que a pintura corporal, somada a resina dessa palmeira ajuda a segurar a alma da criança no seu corpo.

Quando uma criança adoece os Assurini procuram imediatamente o posto de saúde, mas antes utilizam os remédios feitos com ervas medicinais, para curar gripe, dores, entre outras doenças.

Quando criança fica doente a gente tem remédio pra curar, tem o remédio cipó, que as pessoas chamam escada de jabuti, ai a gente corta mercalha todinho ferventa e faz chá, não adoça não é amarga ai como a criança é verdinha dá pra ela com dedo mesmo, mete o dedo e deixa pingar na boca dele 4 pingo, ai vai vendo que a criança está melhorando continua fazendo o remédio até para a dor (...). Nos temo muito remédio no mato, mas as pessoas se confiam mas no medicamento de fora. Mas ai nos perdemos duas pessoas por causa do remédio da cidade, porque nos tinha remédio aqui pra mordida de cobra. Então nós perdemos duas pessoas o Nakawaé e o filho dele. ${ }^{32}$

Segundo Pinto, a medicina ao se afastar do campo religioso levou consigo construções simbólicas e espirituais que com o tempo se tentou excluí-las. A medicina ocidental busca explicar as enfermidades somente através da reação, afirmando que o meio simbólico não interfere no físico. Entretanto, os curandeiros ou os terapeutas tradicionais não separam o físico do espiritual, isso porque se acredita que a pessoa doente está inserida em um meio social e a doença faz com que esse meio social se desestruture, e assim afete o espiritual. ${ }^{33}$

Os Assuriní ainda mantém esse campo simbólico espiritual de cura através da evocação dos karoaras e da utilização de plantas, sementes e óleos medicinais. Aprenderam com seus antepassados a tirar da natureza o que

serve para pintar". É usado por muitas etnias da América do Sul como pintura corporal. As etnias indígenas da região do Tocantins, no Pará extraem tintura da casca, da madeira e do fruto do jenipapeiro. A pintura corporal feita com a tinta do Jenipapo permanece por aproximadamente quinze dias.

${ }^{30} \mathrm{COHN}$, op. cit., p. 110.

${ }^{31} \mathrm{O}$ inajazeiro é uma palmeira comum na região do Tocantins, cujo fruto, inajá, é bastante utilizada na alimentação desses indígenas, seja em natura ou em forma de mingau.

${ }^{32}$ Fala do Cacique Puraké Assurini, uma das lideranças mais velhas entrevistada na aldeia Trocará, em 09 de outubro de 2015.

${ }^{33}$ PINTO, Benedita Celeste de Moraes. Filhas das Matas: práticas e saberes de mulheres quilombolas na Amazônia Tocantina. Belém: Editora Açaí, 2010, p. 164. 
precisam, e isso não diz respeito somente a alimentação, mas também as folhas, cascarias, raízes, óleos e banhas que ajudam a curar as doenças física e as do espírito. Como podemos observar na fala de Joana Assurini,

Às vezes meu filho gripa, eles gripam aí a gente dá esse mel pra eles, e andiroba, cura a garganta logo dele pra não inflamar, é a mãe mesmo que cura, mãe, pai quem tiver coragem de enfiar o dedo dentro da garganta da criança, põe a andiroba no algodão e passa. ${ }^{34}$

É perceptível na fala dos Assuríni, que as infusões, os chás e banhos feitos de ervas e plantas medicinais perpassam o campo científico, adentram o campo simbólico, composto por um conjunto de crenças e saberes, mesmo que perpassados por interferências da medicina dita oficial.

A pesar da existência de um o posto de saúde na aldeia Trocará, o qual presta assistência aos Assurini, estes ainda preferem os remédios caseiros, produzidos com ingredientes extraídos das matas e manipulados pelos mais velhos da comunidade. Entretanto, é importante ressaltar que o trabalho que os profissionais ligados a este posto de saúde vêm desenvolvendo entre os Assurini se destaca pela orientação preventiva, que propicia o não adoecimento.

O referido posto de saúde presta assistência a população fornecendo remédios farmacêuticos, tratamento dentário, exames que são feitos em Tucuruí. Isso acontece devido a ausência de materiais específicos e profissionais necessários para realizações de alguns exames, principalmente, os relacionados a saúde das mulheres, como exame da mama; exame preventivo contra o câncer do útero; exames e cuidados preventivos do pré-natal, entre outros. As crianças são assistidas com exames rotineiros de fezes e urina, visto que o maior índice de doenças são as verminoses, as micoses e as gripes.

Ao analisarmos a concepção da criança e os cuidados da saúde, percebemos que existem modos e doenças diferenciadas, como as de cunho natural e de espiritual, porém ambas recebem os devidos tratamento, seja através da medicina oficial representada pelo posto de saúde, ou mediante as curas através dos rituais evocatórios do karoaras, feitos por pajés, os quais manipulam técnicas para produzir remédios feitos de folhas, sementes, raízes, resinas, óleos e ervas medicinais retiradas da mata.

$\overline{{ }^{34} \text { Fala de Joana Assurini, }} 32$ anos, entrevistada realizada em 11 de outubro de 2015. 


\section{Considerações finais}

No decorrer deste trabalho, fica evidenciado que ao longo do processo histórico as formas de nascimento ou ato de parir são carregadas de significados, os quais são diversificados de uma sociedade para outra. São questões que transitam muito além do método médico cientifico e permeiam o campo cultural de cada grupo, compondo o parto como um evento cultural.

Muitas transformações aconteceram nesse processo no decorrer do tempo, como por exemplo, atos realizados há alguns séculos por um determinado povo passaram por transformações, fato evidenciado também no que diz respeito ao nascimento e as formas de nascer, devido a incorporação de novas práticas que foram surgindo, a modernização da ciência ou mesmo em decorrência da influência de outros povos com quais passaram a ter contatos (dialogar aqui com um autor que trate de tal questão). Fato evidente em diferentes sociedades, como por exemplo, entre povos indígenas brasileiros que no decorrer dos séculos passaram por transformações sociais, culturais e econômicas, dentre elas processo de nascimento. Entre os Assuriní do Trocará, por exemplo, essas mudanças são manifestas atualmente, onde muitas dessas práticas passam por alterações, como é o caso do nascimento das crianças.

No início da formação da aldeia Trocará, por volta da década de 1954, as mulheres e suas crianças eram assistidas durante o parto e o nascimento por parteiras que lhes auxiliavam com energias dos karoaras do bem, tratando com medicamentos naturais extraídos da própria floresta, e os demais cuidados específicos do pós-parto, recomendação de abstenção sexual e ingestão de alimentos ditos remosos. Atualmente, segundo os Assuriní, muitos desses cuidados ou costumes ainda persistem, mas outros já foram modificados.

Conforme foi evidenciado neste estudo, são raros os nascimentos das crianças dentro da aldeia Assuriní com ajuda de parteiras, isso devido à implantação do posto de saúde e a atuação de profissionais ligados a medicina científica, que de certa forma acaba silenciando as ritualizações do ato de nascer entre esse grupo e afastando as parteiras da cena do parto. Fato sentido e contestado principalmente pelos indígenas mais velhos, os quais buscam sempre seguir suas tradições, confrontados ao fato de que as crianças passaram a nascer subsidiados pelos profissionais de saúde, que atuam dentro da aldeia Trocará, e em hospital na cidade de Tucuruí. Na concepção de algumas lideranças indígenas, seria essencial que os dois saberes, tanto o científico, quanto o tradicional, seguissem caminhando juntos. Essas lideranças reconhecem a importância que a atuação de profissionais de saúde representam para a prevenção e manutenção da saúde da população indígena. Contudo, buscam 
manter costumes e traços culturais através dos saberes das parteiras, as quais ajudam o encaminhamento do nascer por meio do parto normal entre os Assuriní. Por outro lado, tais fatores evidenciam as inúmeras transformações que caracterizam a vida de uma determinada sociedade, que se faz atuante no mundo envolvente, seja em torno das questões, sociais, culturais, políticas, religiosas, a exemplo do nascimento.

Artigo recebido para publicação em 30/09/2016

Artigo aprovado para publicação em 21/11/2016 